medical specialities within the same hospital trust, (22\% patients were referred to $\geq 5$ specialities). 3 . Patients required a high number of follow up appointments ( $28 \%$ of patients required $\geq 20$ follow-up visits). 4 . Failed discharges were common; patients were often referred back to the Rheumatology Clinic despite being discharged to primary care. 5. Patients had a significant number of comorbidities, reflected by polypharmacy. (36\% of patients were prescribed $\geq 5$ medications). 6 . Disability was high ( $20 \%$ of patients reported severe mobility problems). Conclusion: This study shows that patients with hEDS referred to UCLH have significant levels of disability, opioids use and polypharmacy especially for a relatively young population of patients. They need a complex interdisciplinary approach in a timely manner. In order to minimise delays and allow earlier diagnosis and intervention, we have recently adopted a multidisciplinary team approach, including pain specialists, rheumatologists, psychologists, physiotherapists, nurse specialists, urogynaecologists and neurogastroenterologists. This allows more coordinated and efficient care and incorporates an EDS-specific pain management programme. Specialised services for complex hEDS cases should be established and adequately resourced. Moreover, it would be cost effective to commission a patient-centred "one-stop-shop" service, where patients, who often travel from long distances with severe disabilities, can be seen by multiple specialities in a single visit.

References:

[1] Bennett, S., Walsh, N., Moss, T. and Palmer, S. (2019). Understanding the psychosocial impact of joint hypermobility syndrome and Ehlers-Danlos syndrome hypermobility type: a qualitative interview study. Disability and Rehabilitation, pp.1-10. Healthwatch Calderdale. (2019). Hypermobility Syndromes Project - Healthwatch Calderdale.

[2] Tinkle, B., Castori, M., Berglund, B., Cohen, H., Grahame, R., Kazkaz, H. and Levy, H. (2017). Hypermobile Ehlers-Danlos syndrome (a.k.a. Ehlers-Danlos syndrome Type III and Ehlers-Danlos syndrome hypermobility type): Clinical description and natural history. American Journal of Medical Genetics Part C: Seminars in Medical Genetics, 175(1), pp.48-69.

Disclosure of Interests: None declared

DOI: 10.1136/annrheumdis-2020-eular.4589

\section{SAT0516 CLINICAL CHARACTERISTICS AND PROGNOSTIC FACTORS IN PATIENTS WITH SECONDARY HEMOPHAGOCYTIC SYNDROME}

C. A. Egües Dubuc ${ }^{1}$, A. De Diego ${ }^{1}$, P. Cabrera Miranda ${ }^{2}$, N. Alcorta Lorenzo ${ }^{1}$, J. A. Valero Jaimes ${ }^{1}$, J. R. Furundarena Salsamendi ${ }^{3}$, O. Maiz-Alonso ${ }^{1}$, L. M. Lopez Dominguez ${ }^{1}$, E. Uriarte Isacelaya ${ }^{1}$, J. J. Cancio Fanlo ${ }^{1}$, J. Calvo ${ }^{4}$, J. M. Belzunegui Otano ${ }^{1} .{ }^{1}$ Donostia University Hospital, Rheumatology, San Sebastian, Spain; ${ }^{2}$ University Hospital 12 October, Preventive medicine and public health, Madrid, Spain; ${ }^{3}$ Donostia University Hospital, Haematology, San Sebastian, Spain; ${ }^{4}$ Araba University Hospital, Rheumatology, San Sebastian, Spain

Background: The Hemophagocytic Syndrome (HPS) had a mortality rate between $20 \%$ and $90 \%$. The mortality of HPS secondary to autoimmune diseases (AID) is lower than hemato-oncological diseases (HOD). In general, the $\mathrm{HOD}$, thrombocytopenia, age, and a prolongation of prothrombin are considered to be an adverse prognostic factor.(1)

Objectives: To describe and identify differences between patients who survived and did not survive to HPS during hospital admission to a tertiary hospital between 2005 and 2019 .

Methods: This is a retrospective observational study. All patients who met the diagnostic criteria for LHH were included, or who presented haemophagocytic cells in the bone marrow biopsy, or who had diagnosis of HPS in the hospital discharge report.(2) Demographic, clinical, analytical, etiological, underlying disorder and prognosis variables were collected. Continuous variables are described with the mean or median according to the degree of normality. Kruskal Wallis, Fisher test and Mann-Whitney $U$ test were used for the bivariate analysis, and also a multivariate logistic regression analysis was performed.

Results: Thirty patients with HPS were included. They were distributed in 5 subgroups (Table 1). Overall mortality was $43.3 \%$, statistically significant higher in the HOD [8 patients (66.7\%); p 0.029]. Also, they were divided into 2 groups (survivor vs. non-survivor; Table 2). In the multivariate model the age and INR prolongation were confirmed to be independently associated with the outcome of mortality.

\section{Table 1. Etiology of HPS}

\begin{tabular}{lcc}
\hline Etiology & $\mathbf{n = 3 0}$ & Mortality \\
\hline AID & $\mathbf{1 0}$ & $\mathbf{n = 1}$ \\
Systemic lupus erythematosus & 5 & 1 \\
Adult Still's Disease & 3 & No \\
Rheumatoid arthritis & 1 & No \\
Sclerosing Disease IgG4 & 1 & No \\
HOD & 12 & $\mathbf{n}=\mathbf{8}^{\star}$ \\
Non-Hodgkin's lymphoma & 3 & 1
\end{tabular}

Table 1. Etiology of HPS

\begin{tabular}{lcc}
\hline Etiology & $\mathbf{n = 3 0}$ & Mortality \\
\hline Myelodysplastic syndrome & 3 & 2 \\
Acute leukemia & 3 & 3 \\
Extranodal NK cell lymphoma & 1 & 1 \\
Multiple Myeloma & 1 & No \\
Probable lymphoproliferative process & 1 & 1 \\
Infectious diseases & $\mathbf{2}$ & $\mathbf{n}=\mathbf{1}$ \\
Pneumocystis carinii in patient with H.I.V. & 1 & No \\
Campylobacter yeyuni & 1 & $\mathbf{n}=\mathbf{0}$ \\
Glyoblastoma multiforme with temozolomida & $\mathbf{1}$ & $\mathbf{3}$ \\
HPS without defined aetiology & $\mathbf{5}$ & \\
HIV: Human Immunodeficiency Virus, NK: Natural Killer. ${ }^{*} \mathrm{p}=0,029$ & \\
\hline
\end{tabular}

Table 2. Characteristics and differences between survivor and non-survivor groups

\begin{tabular}{|c|c|c|c|c|c|c|c|}
\hline \multirow[b]{2}{*}{$\mathbf{n}$} & \multicolumn{2}{|l|}{ Total } & \multicolumn{2}{|c|}{$\begin{array}{c}\text { Non- } \\
\text { survivor }\end{array}$} & \multicolumn{3}{|c|}{ survivor } \\
\hline & 30 & & 13 & & 17 & & $\mathrm{p}<0,05$ \\
\hline Age & 55,5 & $\pm 18,3$ & 68 & $58,2-74,5$ & 40 & $34-57$ & 0,043 \\
\hline Women & 16 & $53,3 \%$ & 7 & $61,5 \%$ & 9 & $47,1 \%$ & 1,00 \\
\hline Comorbidities $(\geq 2$ ) & 5 & $16,7 \%$ & 2 & $15,4 \%$ & 3 & $17,6 \%$ & 1,000 \\
\hline Hospital stay & 35,5 & $20-60,8$ & 29 & $15,5-39$ & 13 & $8-17$ & 0,563 \\
\hline Splenomegaly & 16 & $53,3 \%$ & 7 & $53,8 \%$ & 9 & $52,9 \%$ & 1,000 \\
\hline Hepatomegaly & 10 & $33,3 \%$ & 5 & $38,5 \%$ & 5 & $29,4 \%$ & 0,705 \\
\hline $\mathrm{Hb}(\mathrm{g} / \mathrm{dL})$ & 7,1 & $6,4-7,9$ & $710 \%$ & $6,2-7,8$ & 7,1 & $6,6-7,8$ & 0,094 \\
\hline Pt $\left(\times 10^{9} / L\right)$ & 13500 & $\begin{array}{l}5000- \\
52500\end{array}$ & 16000 & $11000-44000$ & 12000 & $\begin{array}{l}5000-99 \\
000\end{array}$ & 0,281 \\
\hline Pt $\leq 100000$ & 25 & $83,3 \%$ & 13 & $100 \%$ & 12 & $70,6 \%$ & 0,052 \\
\hline Leu $\left(\times 10^{9} / L\right)$ & 1250 & $238-3153$ & 1300 & $150-3940$ & 1400 & $200-3340$ & 0,457 \\
\hline Neu $\left(\times 10^{9} / L\right)$ & 615 & $0-1550$ & 1290 & $20-3300$ & 650 & $0-1400$ & 0,805 \\
\hline $\mathrm{Fb}(\mathrm{mg} / \mathrm{dL})(\mathrm{n}=24)$ & 171 & $111-358$ & 167,00 & $106-253$ & 169,00 & $103-451$ & 0,796 \\
\hline Fer $(n g / m L)(n=28)$ & 15330 & 5 434-38 & 29063 & $5728-74604$ & 13225 & $8287-28$ & 0,108 \\
\hline & & 284 & & & & 729 & \\
\hline $\mathrm{Tg}(\mathrm{mmol} / \mathrm{L})$ & 341 & $226-438$ & 254,00 & $184-382$ & 471,00 & $341-604$ & 0,053 \\
\hline GOT (U/L) & 139 & $77,5-406,3$ & 133,00 & $101-513$ & 179,00 & $101-512,5$ & 0,483 \\
\hline GPT (U/L) & 162 & $46-389$ & 109,00 & $41-333$ & 199,00 & $99-298$ & 0,198 \\
\hline INR $(n=29)$ & 1,5 & $1,1-1,9$ & 2,1 & $1,2-3,7$ & 1,5 & $1,1-1,6$ & 0,028 \\
\hline
\end{tabular}

$\mathrm{Hb}$ : Hemoglobin, Pt: platelets, Leu: leukocytes, Neu: neutrophils, Fb: fibrinogen, Fer: ferritin Tg: triglycerides, GOT: aspartate aminotransferase, GPT: alanine aminotransferase

Conclusion: The HOD presented higher mortality. The non-survivor group presented a longer INR prolongation and a higher age at the time of diagnosis.

References:

[1] Parikh SA. Prog. factors and outcomes of adults with HLH. Mayo Clin Proc. 2014;89:484-492.

[2] Henter JI. HLH-2004: Diag. and therapeutic guidelines for HLH.Pediatr Blood Cancer. 2007;48:124

Disclosure of Interests: César Antonio Egües Dubuc: None declared, Andrea De Diego: None declared, Patricia Cabrera Miranda: None declared, Nerea Alcorta Lorenzo: None declared, Jesús Alejandro Valero Jaimes: None declared Jose Ramon Furundarena Salsamendi: None declared, Olga Maiz-Alonso: None declared, Luis Maria Lopez Dominguez: None declared, Esther Uriarte Isacelaya: None declared, Jorge Jesús Cancio Fanlo: None declared, Jaime Calvo Grant/research support from: Lilly, UCB, Consultant of: Abbvie, Jansen, Celgene, Joaquin Maria Belzunegui Otano: None declared

DOI: 10.1136/annrheumdis-2020-eular.5855

\section{\begin{tabular}{|l|l}
\hline SAT0518 CANAKINUMAB TREATMENT IN ADULT PATIENTS \\
\hline
\end{tabular} WITH FAMILIAL MEDITERRANEAN FEVER: A SINGLE- CENTER STUDY}

S. Ugurlu ${ }^{1}$, B. H. Egeli ${ }^{1}$, O. Selvi ${ }^{1}$, B. Ergezen ${ }^{1}$, A. Hadzalic ${ }^{1}$, H. Ozdogan ${ }^{1}$. ${ }^{1}$ Istanbul University-Cerrahpasa, Istanbul, Turkey

Background: Familial Mediterranean Fever (FMF) is the most common autoinflammatory disease characterized by recurrent, self-remitting attacks of fever, serositis, arthritis, and erysipelas-like erythema. Canakinumab is an Interleukin- $1 \beta$ inhibitor that is shown to be effective and safe in treating colchicine resistant FMF patients.

Objectives: The main objective of this study is to present the single tertiary center experience of adult FMF patients who received Canakinumab.

Methods: The study is a retrospective analysis conducted at a tertiary rheumatology center experienced in FMF. The patients who had a clinical diagnosis of FMF and who were treated with at least a single subcutaneous injection of canakinumab were 